\title{
Contrasts Between Classes of Assets in Fixed Investment Equations as a Way of Testing Real Option Theory
}

\author{
Ciaran DRIVER \\ Tanaka Business School, Imperial College, University of London, SW7 2AZ (U.K.) \\ (c.driver@imperial.ac.uk) \\ Paul TEMPLE \\ Department of Economics, University of Surrey, Guildford, GU2 7XH (U.K.) \\ (p.temple@surrey.ac.uk)

\section{Giovanni URGA} \\ Centre for Econometric Analysis, Faculty of Finance, Cass Business School, 106 \\ Bunhill Row, London EC1Y 8TZ (U.K.) \\ (g.urga@city.ac.uk)
}

This version: 5 May, 2005

This paper tests the power of real options theory to explain investment under uncertainty, exploiting differences in the degree of irreversibility between machinery and buildings. It reports estimates of investment equations for each asset class using a large sample of UK manufacturing industries, with results that are consistent with the predictions of real options theory. Additionally, using a specially constructed industryspecific measure of irreversibility for machinery investment, the paper provides further confirmation of the empirical relevance of real options.

KEY WORDS: Investment, Irreversibility, Real Options, Uncertainty, Panel Data.

J.E.L. classifications: E22, C23 


\section{INTRODUCTION}

Few topics in economics have generated such a vast literature as investment under uncertainty. However, it has proved very difficult to use the burgeoning theory in a way that imposes order on the applied results. It is easy to show that uncertainty can reduce the incentive to invest. If the firm can wait without severe penalties, and if committing now involves sunk costs, there is clearly an advantage to waiting that reduces the incentive to current investment. However, this conclusion can be reversed where costs are not sunk (i.e. there is a put option) or where waiting involves a penalty, as in the case of a firm being unable to respond to a future favourable shock because of some binding constraint (in respect for example of input supplies). In such cases the firm may be said to lack a call option which could otherwise be exercised e.g. by the purchase of inputs at a pre-arranged option price. It is therefore the overall balance of effects arising from both the put option and the call option which will determine the sign of the influence of uncertainty.

Our intention in this paper is to test the predictions of real options theory by discriminating between the cases where irreversibility (the lack of a put option) or expandability (the presence of a call option) matter most. We argue below that there are important differences in this regard between broad classes of assets - machinery and buildings - that have implications for the effect of uncertainty on investment in each asset type. To anticipate our results we find that machinery investment is more influenced downwards and less influenced upwards by uncertainty than is building investment. The preponderance of negative results in the literature may reflect the weight of studies which estimate machinery investment equations or aggregate equations that are dominated by the machinery component. 
The paper is organised as follows. The next section reviews the evidence for maintaining a distinction between the characteristics of our two asset types. Section 3 outlines the real options approach and provides hypotheses that contrast building and machinery investment under option theory. Section 4 specifies an investment equation, while Section 5 presents the results of a set of investment equations for both classes of capital goods using seemingly unrelated regression estimation (SURE) and Panel estimation; these results are then interpreted and discussed. Section 6 expands the analysis by using a specially constructed industry-specific index of irreversibility for machinery which allows us to check for interaction effects between irreversibility and uncertainty for this class of investment. Section 7 concludes.

\section{CONTRASTING ASSET TYPES}

In this section we present evidence that our chosen two assets - machinery and buildings - are characterised by differences in their respective levels of both irreversibility (sunk cost) and expandability.

In the empirical literature, sunk cost has been estimated at industry level from data on minimum efficient scale for new entry and auxiliary indicators such as the extent of rental markets, depreciation rates and existence of second-hand markets (Sutton 1991; Worthington 1995; Kessides 1990a; Ghosal 2002). In this paper we are more concerned with assigning an irreversibility classification to different assets rather than to different industries, though we also consider variation by industry in Section 6 below.

What is the evidence that machinery investment is more irreversible than buildings? It is often thought that markets for general machinery are frictionless, given that assets can be disposed of through organised second hand sellers and not only at 
auctions. Indeed some classic references in the literature assume the existence of perfect second hand markets in order to ascertain the depreciation pattern of specific classes of machinery (e.g. Hulten and Wykoff 1981). However, recent research has emphasised just how imperfect such markets are, due to industry-specificity of the assets and to thinmarket effects. One study, based on an examination of equipment disposals after the closure of US Aerospace plants in the 1990s, found substantial industry specificity, a large discount relative to replacement cost, and a lengthy selling time (Ramey and Shapiro 2001). A similar study of the Swedish metal working industry - but concerned with routine decisions rather than those linked to a major sell-off - found that the sunk cost component varied between $50 \%$ and $80 \%$ of the replacement cost: a majority of items - many comparatively new - were scrapped at a negligible price rather than being sold (Asplund 2000). This suggests both industry and firm specificity. Note moreover that our data on machinery assets also include investment in process plant, which again is likely to be highly specific to its industry.

Turning now to buildings assets, it seems unlikely that the physical specifications are likely to change much between firms in the same narrow industry, implying that less firm specificity is involved than for machinery. There may also be less industrial specificity, given that buildings can easily be adapted for different purposes and frequently are. This question was investigated by Worthington (1995) who used the proportion of rental payments in capital costs and the proportion of capital expenditure on used assets as inverse proxies for irreversibility. Computing these measures separately for equipment and structures indicate that "equipment expenditures are more 'sunk' than structures...” (p.59).

Additional evidence that buildings are less specific in use comes from a unique series of official data on gross increases and decreases in industrial floor space over the 
period 1982-5 for England (Government Statistical Service, various issues). The data show that approximately $40 \%$ of the gross increase was due to a change to industrial use from other categories of floorspace (warehouses; shops; restaurants; and commercial offices). The corresponding data on gross decreases in industrial floorspace during the same period show that demolitions accounted for only one quarter of the decline. In the U.S., Ramey and Shapiro (2001) found that no buildings were sold in the aerospace closures studied. The authors explain this by the observation that "not selling buildings is not unusual for plant closings that are more than 25 years old... [Due to environmental costs] they simply raze the buildings to the ground” (P.965). Our results suggest that demolition is not as common as this, perhaps because many industries have less dedicated buildings than aerospace or because of greater pressure on land use in the densely populated UK. The frequent change in use in both directions suggests that building assets are neither highly firm specific nor even highly sector specific in most cases. Indeed, using the data source cited above on UK floorspace, we can compare the demolition ratio of industrial floorspace with that for commercial offices and for shops and restaurants. The ratios are $0.24,0.24$ and 0.28 respectively, suggesting that the three categories are similar in respect of the decision to sell or scrap. This supports the view that industrial buildings are not highly specific as it is widely recognised that the offices and shops are fungible categories of assets in the sense of being easy to adapt for use by other owners.

Further support for our hypothesis on the relative irreversibility of these assets is provided by data on second-hand sales. The annual UK Census of Production contains current values by 3-digit industry of both disposals (the sale for any purpose of secondhand buildings and industrial land as well as plant and machinery) and acquisitions (which may be either new or second-hand). We use these data to construct a timeaveraged ratio (1979-89) of disposals to acquisitions for the two classes of assets: 
machinery and buildings, where the buildings category includes industrial land. This is plotted in Figure 1, from which it may be seen that the ratio is nearly always substantially higher for the land and buildings category than for machinery. This again supports the argument that sunk costs are higher for machinery.

\section{[Insert Figure 1 about here]}

As a final support of this dichotomy between machinery and building assets there is at least one piece of indirect evidence arising from work on entry barriers. Kessides (1990b), shows that machinery investment is more effective than building in impeding entry. This is even after taking account of the profit level of incumbents, growth of industry demand, and the required scale of entry. Quite plausibly, this is because the sunk component of the former is greater. Indeed the finding is that while industry variation in the upper bound of sunk cost for machinery and equipment exerts a significant negative effect on entry, there is no significance found for the corresponding buildings variable.

The preceding discussion has shown that machinery is characterized by greater irreversibility than buildings. It also seems highly likely (although admittedly there is less evidence here to cite) that building assets display less expandability than machinery. This is first because machinery purchases are less lumpy than buildings and can often be bought from stock in any number without long delivery lags. By contrast, buildings alterations and expansions require design, planning approval and site availability so that expandability may not even be feasible in some circumstances. A further point of contrast concerns the cyclicality of supply price for the two assets. The UK building deflator is highly cyclical due to labor intensity and a reliance on heavy materials such as bricks and cement that have high transport costs. Firms who fail to add sufficient capacity at the right time can expect to pay a high premium if they have to bid for expansion as demand strengthens. 


\section{INVESTMENT THEORY AND REAL OPTIONS}

Until quite recently, investment theory has been dominated by models of continuous adjustment implied by the convex cost of adjustment approach. Such models have typically been solved using stock market valuation for the marginal value of a unit of capital; by representing that marginal value by a vector autoregression; or by invoking rational expectations for the value of marginal q. However such standard models have tended to disappoint in empirical estimation (Chatelain and Teurlai 2001; Driver and Meade 2001).

Recently a class of models has been proposed which focuses on potential discontinuities in the adjustment process (Chirinko and Schaller 2002). Much of this literature focuses on the "irreversibility premium" or the multiple by which Tobin’s q must be adjusted to take account of the absence of a put option when investing (Dixit and Pindyck 1994, p.146). It is not, however, clear that the premium is always positive: indeed we may talk of an "expandability" premium when the former is negative. This complication is identified in the contribution of Abel et al. (1996). In a two-period investment model, the ex-ante investment may no longer be appropriate in the light of the realisation of the stochastic variable $e$ (see Eq. (1) below). In the second period, one might prefer to sell part of the capital invested or exercise a right to buy more at a prearranged price. Here, the ex-post price for a disequilibrium adjustment, whether up or down, is distinguished from the ex-ante purchase price. This complication results a premium to be added to the Jorgenson user cost of capital term (Abel et al., 1996, expression 17):

$\left(p-p^{-}\right) F\left(e_{L}\right)+\int_{e_{L}}^{e_{H}}\left[p-R_{K}(K, e)\right] d F(e)-\left(p^{+}-p\right)\left[1-F\left(e_{H}\right)\right]$ 
Here $\mathrm{p}, \mathrm{p}^{-}, \mathrm{p}^{+}$are the first period purchase price of a unit of capital and the corresponding (ex-post) selling and buying prices respectively. The first and the third term reflect that not only may excess capital have to be disposed of at a distress price $\left(p^{-}\right)$but deficient capital may need to be installed at a premium price $\left(p^{+}\right)$. The middle (integral) term reflects the expected divergence between price and marginal return where the discrepancy is not sufficient to induce contraction or expansion. $F(e)$ is the distribution function of the underlying stochastic variable and $R_{K}$ is the marginal return on capital installed which may have to be evaluated at a non-optimal level of the capital stock. The terms $e_{L}$ and $e_{H}$ are the critical values of the stochastic variable at which the original capital is no longer optimal ex post, and which signal the need to adjust the capital stock at a disequilibrium price. The effect of this modification is to show the possibility of an irreversibility option premium or an expandability option premium i.e. the hurdle rate can lie above or below the usual cost of capital. The irreversibility premium will exist where deferral options effects are dominant i.e. the fear of being locked into uneconomic commitments. The expandability premium will exist where the dominant concern is the ability to ensure capacity in the event of favorable demand.

In order to derive specific hypotheses we note that the incentive to invest depends on the level of the two exercise prices $p^{-}$and $p^{+}$. This can be shown by differentiating the shadow value of capital (termed $q$ in Abel et al. 1996) with respect to $p^{-}$and $p^{+}$. Since the only terms in these variables are the terms $\left(p-p^{-}\right) F\left(e_{L}\right)$ and $-\left(p^{+}-p\right)\left[1-F\left(e_{H}\right)\right]$ it is obvious that the marginal value of capital is increasing in both $p^{-}$and $p^{+}$. Intuitively, an increase in the resale price $\left(p^{-}\right)$reduces irreversibility and increases the incentive to invest whereas an increase in the contingent purchase price $\mathrm{p}^{+}$ 
reduces the value of the call option and increases the marginal value of current investment. (Abel et al. 1996, pp. 760-761).

Abel et al (1996) derive the cumulative probability density function (cdf) of the marginal return to first period capital $R_{K}(K, e)$ as a function of the underlying distribution of e. As noted earlier it may be optimal to adjust the first period capital expost and these exchanges are effected at the exercise prices $p^{-}$and $p^{+}$. The expectation of first period marginal returns to capital has to take into account these ex-post adjustments. Abel et al (1996) plot the cumulative density function of $R_{K}(K, e)$ with critical values $p^{-}$and $p^{+}$cutting off areas corresponding to the values of the put and call options. We reproduce that plot in Figure 2 below with the modification that we show two distributions corresponding to a mean-preserving spread in the outcome variable $e$ that translates into greater dispersion in the marginal return. The distribution with the higher dispersion has higher values of both put and call options. However, what is of interest in our analysis is how the differences in option values behave as we shift attention from one class of assets to another. We have argued earlier that machinery is characterised by a low $p^{-}$and low $p^{+}$relative to building i.e. there is both greater irreversibility and greater expandability for machinery. In Figure 2, therefore, we also depict the distribution tails for both asset classes. A conceptual shift of the cut-off points from the full vertical lines to the dashed vertical lines corresponds to a shift from building to machinery.

\section{[Insert Figure 2 about here]}

For any given project, the effect of increased uncertainty on the incentive to invest is therefore ambiguously signed. Greater uncertainty tends to increase the weight of both 
tails, i.e. the value of both the put option and the call option is increased. A higher put option value (with a bigger left tail) reflecting the increased likelihood of exercising the opportunity to adjust downwards at the strike price $\mathrm{p}^{-}$increases the incentive to invest relative to the no option case while a larger call option value (bigger right hand tail) reflecting the increased likelihood of exercising the opportunity to adjust upwards ex-post at the $\mathrm{p}^{+}$strike price reduces the incentive to invest relative to the no option case. The net effect on investment of increased uncertainty is thus ambiguous with a positive effect coming from the increased put option and a negative effect from the increased call option (Abel et al. 1996, p.773; Bar-Ilan and Strange 1996).

However the differential effect of increased uncertainty between buildings and machinery is not ambiguous. As is made clear in Figure 2, greater uncertainty increases the call option value of machinery by a greater amount than it does the call option of building. In the figure, this difference is given by the cross-hatched area MNOP. By contrast, greater uncertainty increases the put option of building by more than it does the put option of machinery (the difference here being given by the cross-hatched area RSTU). This contrast opens up a possibility to test real options predictions as outlined below.

To set up a test that discriminates between the effect of uncertainty on our two asset classes, we first identify separate panels with positive and negative uncertainty effects. The negative signed cases will be dominated by the increased call option effect. Focusing on this (the right hand tail) the effect of increased uncertainty is to increase the value of the call option but to increase it more for machinery relative to building. Thus increased uncertainty will have a differential negative effect between the assets with the negative effect being more pronounced for machinery.

A similar analysis may be made of the panels with positive uncertainty effect 
which will be dominated by the increased put option effect. Focusing now on the left hand tail, the effect of increased uncertainty is again to increase the value of the put option but to increase it more for building relative to machinery. Thus increased uncertainty will have a differential positive effect between the assets with the positive effect being more pronounced for building. Note that we ignore the effect of convexity or concavity on the marginal return between the critical points as there is no strong prior as to differences in this between the asset types.

We may summarise the predictions of the above analysis in a simple matrix corresponding to the industry panels we investigate below:

\section{[Insert Table 1 about here]}

\section{MODEL SPECIFICATION}

To test the existence of real options effects we contrast investment equations for both machinery and buildings for a set of UK industries. Given the difficulties in specifying and estimating Euler equation models (Garber and King 1983; Chirinko 1993) we have recourse to a standard flexible accelerator model which incorporates direct expectations and survey data from the main UK employers organization, the CBI. As other recent research has argued (e.g. Mairesse et al. 1999) these direct expectations have advantages over the inference of expectations required in the Euler equation approach, especially when used in an error (equilibrium) correction type model.

The survey data (which are publicly available and which feed into the EU industrial database) record investment authorisation rather than actual investment, though these two variables are linked by a well determined realisation function (European Commission, 1997; see also Lamont, 2000, for the accuracy of US intentions data). The data are qualitative, being recorded in the form of the percentage of respondents replying "more" or "less" to the 
level of authorisations planned in the next period. However, a useful result is that the balance of "more" over "less" responses is closely correlated with rates of change: Driver and Urga (2004); Smith and McAleer (1995). The specification for the balance in investment authorisations $\left(A_{t}\right)$ is derived as an optimal response to adjustment costs (see Berndt, 1990; Chirinko, Fazzari and Meyer 1999). We include uncertainty variables along with a set of other relevant variables from the CBI survey (see Appendix 1).

We specify a log-linear accelerator equation linking investment authorisations $A_{t}$ and change in output $\Delta Y_{t}$ : $\log A_{t}=f\left(\log \Delta Y_{t}\right)$ Representing this in equilibrium correction form, specified on the assumption that $A_{t}$ and $\Delta Y_{t}$ may be non-stationary, we have

$\Delta \log A_{t}=\beta_{0}+\beta_{1} \Delta \log \Delta Y_{t}+\beta_{2} \log (A / \Delta Y)_{t-1}+e_{t}$

where $e_{t}$ is an i.i.d. error term.

The dependent variable and both of the terms involving $\Delta Y_{t}$ were constructed as discussed above from the survey data balances of "ups" over "downs" in respect of responses to the authorisation question and the output question. Therefore, these balances represent growth rates $\Delta \log A_{t}$ and $\Delta \log Y_{t}$ respectively, as demonstrated in the literature on survey transformations. Thus the dependent variable may be directly read off the survey information but the terms in $\Delta Y_{t}$ require further transformations of the data as specified in the data appendix. The equilibrium error correction term $\log (A / \Delta Y)_{t-1}$ represents the extent to which authorised investment is tracking incremental output; integrating these terms gives ratio of authorised capital to output or, 
inversely, the capacity utilisation term that is often used in investment equations to proxy an (integral control) equilibrium correction term.

Thus the basic specification (full derivation is reported in Appendix 1) is a modified form of (2):

auth $_{t}=b_{0}+b_{1} y_{t}+b_{2} c u_{t-1}$

where the dependent variable $\left(a u t h_{t}\right)$ is the balance of replies to survey question 3 used to proxy $\Delta \log A_{t}$; the variable $y_{t}$ is the approximation to the second term in (2) derived in the appendix from the survey data, and $c u_{t-1}$ is the lagged capacity utilisation term again derived in the Appendix 1 from the survey data to proxy the third term in (2). Coefficients $b_{1}$ and $b_{2}$ are both expected to be positive.

Equation (3) is the equation which can be directly estimated by the CBI survey data. To obtain the reduced form of the estimated equation, we further assume that investment authorisation is affected by its own lagged values $\left(\sum_{j} a u t h_{t-j}\right)$, by the degree of optimism about the general business situation $\left(o p t_{t}\right)$, by a measure of financial constraints (fi), by the degree of uncertainty $\left(u n c_{t}\right)$, and by the current value of the differenced log term in capacity utilisation $\left(d l c u_{t}\right)$. Since the CBI survey has two kinds of information on output, that is the forward-looking term and the backward-looking term (see Question 8 in Appendix 1), our model includes both forward and backward terms of $y_{t}$, denoted by $y f_{t}$ and $y b_{t}$ respectively. After experimentation, we include only the current value of $y f_{t}$ and both the current and lagged values of $y b_{t}$ in our specification. The reduced form of the equation which we will estimate throughout the paper is: 


$$
\begin{aligned}
& \text { auth }_{i t}=b_{i, 0}+\sum_{j=1}^{m} b_{1, j} \text { auth }_{i, t-j}+b_{2} \text { opt } \\
& i t \\
& b_{7} \text { unc }_{i, t-j}+b_{3} y f_{i, t}+b_{4} y b_{i, t-j}+b_{9} \text { dlcu }_{i, t}+e_{i, t} y b_{i, t-1}+b_{6} c u_{i, t-1}+
\end{aligned}
$$

The explanatory variable measuring industry-level business confidence or optimism (opt) is obtained from replies to question 1 of the Survey. Our uncertainty variable (unc) is based upon the cross-sectional dispersion of beliefs across firms in an industry in regard to optimism for the industry. Assuming a high degree of homogeneity in demand conditions within the industry, cross-section dispersion of beliefs about the same sector may be regarded as a measure of uncertainty. This entropy variable has been used successfully in other contexts involving surveys with three possible replies to measure the extent of disagreement among respondents (Fuchs, Krueger and Poterba 1998; see also Zarnowitz and Lambros 1987; Giordani and Soderland 2003; Lensink et al. 2001). $f i$ is the expected incidence of internal or external financial constraint measured by the percentage giving either of these replies to CBI question 16c (see Appendix 1).

\section{EMPIRICAL RESULTS}

Our initial experiment was the estimation of the unrestricted (slope coefficients varying across equations) seemingly unrelated regression (SURE) model: in the presence of contemporaneous correlation, it is more efficient to estimate all equations jointly rather than separately. Summary result statistics for each industry for both machinery and buildings are given in Appendix 2, which shows that the specification of the investment equations is supported by the data for both Machinery and Building. The coefficients in the SURE equations are generally significant and signed in accordance with expectation and with generally acceptable diagnostics. In order to better understand these results, we 
moved to a more parsimonious representation of the estimates by pooling across industries. Table 2 (columns 2 and 3) reports the preferred pooled models (fixed effects for machinery; random effects for buildings), with the fixed effects for buildings also included for comparability in column 4. These results for the whole panel show an overall negative effect of uncertainty on machinery investment. For the case of buildings the effect is positive but not significant. However, the use of SURE to model the considerable heterogeneity across industries in the buildings sample is further justified by the Breusch and Pagan (1980) test. The null that contemporaneous covariances are zero (see Judge et al 1988, p.455) is rejected, favoring unrestricted SURE (see Table 2).

\section{[Insert Table 2 about here]}

The rejection of homogeneity in the total sample for buildings suggests that it would be useful to split the samples when comparing results across the asset classes. Accordingly, we used the sign of the summed uncertainty (unc) coefficients in the SURE estimation (where jointly significant at the 10\% level) to form two sub-samples with positive and negative uncertainty effects; this produces four sub-samples in all. The idea here is that we can now compare, in line with our earlier theory, the negative results across the asset classes and we can similarly compare the positive results. The results here are presented in the remaining four columns of Table 2. Note that models with (partially) independent stochastic regressors can be estimated via least squares, which provide (consistent) unbiased estimates. Panel estimation methods control for potential selection bias due to the split of the sample.

We find that the negative uncertainty effect is $25 \%$ greater in magnitude for the machinery case ( -0.19 as compared to -0.15 with a t-test of 2.13 on the difference) in line with the hypothesis advanced earlier. If the long-run coefficients are computed, the difference is even greater $(-0.41$ as compared to -0.26$)$. For the panel set relating to the 
positive coefficients, the uncertainty effect is large and significant for buildings but is not statistically significant for machinery at conventional 5\% level. This again accords with expectations. The remaining diagnostics, reported for these equations in Table 2, are mostly acceptable, though the heterogeneity test is failed at $5 \%$ for machinery for the case of negative coefficients. We have thus established our basic hypothesis that negative effects of uncertainty are more pronounced for the more irreversible asset (machinery) while positive effects are more pronounced for building. The latter result is we believe, due not only to the lower irreversibility for building but also to its lower expandability as argued in Section 2.

The robustness of the results may be illustrated by considering a different test. For each industry we sum the uncertainty coefficients for machinery and also for buildings and we take the difference of the summed coefficients between the two asset classes. We use the standard errors of the summed coefficients using the variance-covariance matrix of the SURE estimators and obtain the significance of the difference, whether positive or negative by dividing each industry difference by the square root of the sum of the squared standard errors for machinery and buildings. Using a one-sided 10\% test we identify six industries where the machinery coefficient is significantly more negative than the building coefficient. There are only three industries where the reverse is true. Furthermore the mean difference in the case of the negative differences exceeds that in the case of positives by a factor of more than three [We wish to thank an anonymous referee for suggesting this test] 


\section{ESTIMATING AN IRREVERSIBILITY EFFECT FOR MACHINERY}

We now turn to a more detailed analysis of the machinery equations using industry-specific data on irreversibility of assets from the UK Census of Production data on disposals and acquisitions described in Section 2. We use these data as follows to construct industry-specific measures of irreversibility for machinery. Unfortunately the nature of these data does not allow us to perform a similar exercise for buildings: in this case, the disposals data include the value of the land sold in addition to that of (secondhand) buildings. While it may be that both buildings and land are less irreversible than machinery we have no strong prior as to the relative irreversibility of buildings and land. As the mix between buildings and land varies across our sample of industries varies in an unobserved fashion, any comparable cross section exercise for buildings would be potentially highly misleading.

An intuitive starting point for the machinery case is that the ratio of disposals to acquisitions will be higher where disposals have value. The ratio will be low or close to zero if second-hand markets are thin or non-existent. It would not, however, be entirely appropriate to use the simple ratio of disposals to acquisitions as an indicator of thick markets for disposals. Disposals and acquisitions may be different functions of industry characteristics such as size and growth. We expect a positive correlation between disposals and acquisitions due to the fact that acquisitions will proxy both the size and growth of the industry (the sum of depreciation and growth). As our interest is not in the dynamics we first time-average the data to obtain the mean for each industry of disposals $\left(D_{i}\right)$ and of acquisitions $\left(A_{i}\right)$. Disposals will also depend on the extent to which secondhand goods are marketable in the industry $\left(M_{i}\right)$. Using initially a log-linear specification to illustrate: 
$d_{i}=b_{0}+b_{1} a_{i}+b_{2} m_{i}+e_{i}$

where $e_{i}$ is an error term and lower case letters indicate logs.

Rewriting (5)

$d_{i}-a_{i}=b_{0}+\left(b_{1}-1\right) a_{i}+b_{2} m_{i}+e_{i}$

The $m_{i}$ variable, of course, is unobserved and has to be estimated as a residual. As we have no strong priors as to the functional form of (6) we carried out non-nested testing of linear versus non-linear forms. We rejected the latter in favour of linearity using a range of tests implemented in Microfit 4, including the PE test (MacKinnon, White and Davidson 1983) and the BM test (Bera and McAleer 1989).

The vector of residuals from (6) is an estimate of the extent of second-hand markets for each 3-digit industry. Using a correspondence table from the SIC to the CBI industry set it was then possible to derive measures for the set of $\mathrm{CBI}$ industries which comprise our sample. As there is no strong case for interpreting the residual as a cardinal measure, we use its reverse ranking as an ordinal measure of irreversibility $\left(\mathrm{irra}_{i}\right)$. As a measure for comparison we also compute the reverse ranking of the ratio of the raw timeaveraged figures $\left(D_{i} / A_{i}\right)$. We call this unadjusted measure $\left(i r r b_{i}\right)$. All rankings are detailed in Appendix 3. The rankings seem intuitively plausible. For example, the most irreversible industries include the process ones (chemicals and metals, building materials, rubber, plastic, paper and board, food, drink \& tobacco) which all have a ranking greater than 30; the reversible categories include light engineering industries; publishing; most textiles, clothing, leather and wood industries, all of which have a ranking less than 20.

Next, we ran the machinery panel regression for the full set of industries including both the uncertainty measure (unc) and the interaction of unc with the measure of irreversibility (irra and irrb). The results are shown in Table 3. Extra lags on unc did not 
contribute any explanatory power. There is clear significance for the interaction effect with irra. It is signed negatively, in accordance with the prior expectation that greater irreversibility would strengthen the negative uncertainty effect. The interaction using the unadjusted ratio (irrb) is however significant only at the $10 \%$ level.

The results of these interactions may be compared to those of Guiso and Parigi (1999). These authors, using a different specification obtained similar findings to ours, using a set of irreversibility measures that are based on ease of disposal or availability of secondhand markets. Although no direct industry by industry comparison with the current results is possible, using a split sample based on access to second-hand markets, the authors find that "uncertainty is especially relevant whenever it is costly to dispose of excess capital” (p.208).

\section{[Insert Table 3 about here]}

\section{CONCLUSIONS}

In the light of real options theory, this paper suggests that a comparison of investment across two classes of assets may provide important insights into the role of uncertainty. Specifically, we hypothesize that for machinery, investment would be more in the nature of a sunk cost than is the case for buildings, while buildings would be characterized by lower expandability due to higher expansion cost premia.

To test the above hypothesis, we report estimates of investment authorization equations for both machinery and buildings, focusing on a contrast between the (standardized) magnitude, sign and significance of the uncertainty terms. We compared the results using SURE and Panel estimation, finding that the effect of uncertainty is different between machinery and buildings. Several results stand out when both the asset panels are split into those industries with positive coefficients and those with negative coefficients. Specifically, the negative effect of uncertainty on machinery investment is 
much greater than for building for those industries with negative coefficients in the SURE estimation. At the same time the positive effect of uncertainty is strongly significant for building and not significant for machinery for those industries with positive coefficients in the SURE estimation. These results support the theory of deferment options operating more strongly in the case of machinery and for expansion options operating more strongly in the case of buildings.

Additional results were presented for machinery for which it proved possible to interact a specially constructed industry-specific proxy for irreversibility with the industry-specific uncertainty term. This interaction was negative and significant in line with the expectation of real options theory that irreversibility should amplify the negative influence of uncertainty on fixed investment for this asset class.

Finally we restate the major overall finding of this study. This is that the difference in investment behavior under uncertainty between machinery assets and building assets may be explained is explainable as a contrast between the existence of deferment options and expansion options. 


\section{ACKNOWLEDGMENTS}

We thank participants in seminars at the Australian National University, Canberra, the University of Melbourne, and in the $10^{\text {th }}$ International Conference on Panel Data in Berlin. We wish to thank the Editor, Torben Andersen, the Co-Editor, Alistair Hall, an Associate Editor and an anonymous referee for useful comments and suggestions that helped greatly to improve the paper. The usual disclaimer applies. K. Imai and, especially, J. Munoz provided superb research assistance. ESRC funding under grant N. R000223385 is gratefully acknowledged. 


\section{REFERENCES}

Abel, A.B., Dixit, A.K., Eberly, J.C. and Pindyck, R.S. (1996), "Options, the value of capital and investment," Quarterly Journal of Economics, August, 753-777.

Asplund, M. (2000), "What fraction of a capital investment is sunk cost," Journal of Industrial Economics, 48, 287-304.

Bar-Ilan, A. and Strange, W.C. (1996), “Investment lags,” American Economic Review, 86, 610-622.

Bera, A.K. and McAleer, M. (1989), "Nested and non-nested procedures for testing linear and log-linear regression models,” Sankhya B: The Indian Journal of Statistics, 51, 212224.

Berndt, E.R. (1990), The Practice of Econometrics: Classic and Contemporary, Massachusetts: Addison Wesley.

Breusch, T. S. and Pagan, A. R. (1980), “The Lagrange multiplier test and its applications to model specification in econometrics”, Review of Economic Studies, 47, 239-254.

Chatelain, J.B. and Teurlai, J.C. (2001), “Pitfalls in investment Euler equations,” Economic Modelling, 18, 159-179.

Chirinko, R.S. (1993), "Business fixed investment spending: modelling strategies, empirical results and policy implications, Journal of Economic Literature, 31, 1875-1911

Chirinko, R.S., Fazzari S.M. and Meyer, A.P. (1999), "How responsive is business capital formation to its user cost? An explanation with micro data," Journal of Public Economics, $74,53-80$.

Chirinko, R.S. and Schaller, H. (2002), “The irreversibility premium,” paper presented at the 2002 American Economic Association annual conference, Atlanta, 4-6, January.

Dixit, A. and Pindyck, R. (1994), Investment under Uncertainty, Princeton: Princeton University Press.

Driver, C. and Meade, N. (2001) "Persistence of capacity shortage and the role of adjustment costs," Scottish Journal of Political Economy, 48, 27-47.

Driver, C. and Urga, G. (2004), "Transforming qualitative survey data: performance comparison for the U.K.," Oxford Bulletin of Economics and Statistics, 66, 71-89.

European Commission (1997), "The joint harmonised EU programme of business and consumer surveys,” European Economy, 6. 
Fuchs, V.R., Krueger A.B. and Poterba, J. M. (1998), "Economists' views about parameters, values, and policies: survey results in labor and public economics," Journal of Economic Literature, 36, 1387 -1425.

Garber, P. and King R. (1983), "Deep structural excavation? A critique of Euler equation methods”, NBER Working Paper 31.

Ghosal, V. (2002), "The impact of uncertainty and sunk costs on firm dynamics and industry structure: evidence from the US manufacturing sector,” mimeo.

Giordani, P. and Soderland, P. (2003), "Inflation forecast uncertainty," European Economic Review, 47, 1037-1059.

Government Statistical Service (1986), "Commercial and industrial floorspace statistics: England 1982-5," Department of the Environment 1986 \#14, HMSO.

Guiso, L. and Parigi, G. (1999), "Investment and demand uncertainty," The Quarterly Journal of Economics, 115, 185-227.

Hulten, C.R. and Wykoff, F. C. (1981), "The estimation of economic depreciation using vintage asset prices: an application of the Box-Cox power transformation," Journal of Econometrics, 15, 367-396.

Judge, G.G., Hill, R.C., Griffiths, W. E., Lutkepohl, H., and Lee, T.C. (1988), Introduction to Theory and Practice of Econometrics, Second Edition, John Wiley.

Kessides, I. N. (1990a), “Market concentration, contestability, and sunk costs,” Review of Economics and Statistics, 72, 614-622.

Kessides, I. N. (1990b), "Towards a testable model of entry: a study of US manufacturing industries,” Economica, 57, 219-238.

Lamont, O. A. (2000), "Investment plans and stock returns,” Journal of Finance, 55, 2719-2745

Lensink, R., Bo, H. and Sterken, E. (2001), Investment, Capital Market Imperfections and Uncertainty, Edward Elgar.

MacKinnon, J.G., White, H. and Davidson, R. (1983), "Tests for model specification in the presence of alternative hypothesis: some further results," The Journal of Econometrics, 21, 53-70.

Mairesse, J., Hall, B. H. and Mulkay, B. (1999), "Firm-level investment in France and the United States: an exploration of what we have learned in twenty years,” NBER Working Paper 7437.

Ramey, V.A. and Shapiro, M. D. (2001), "Displaced capital: a study of aerospace plant closings,” Journal of Political Economy, 109, 958-992. 
Smith, J. and McAleer, M. (1995), "Alternative procedures for converting qualitative response data to quantitative expectations: an application to Australian manufacturing," Journal of Applied Econometrics, 10, 165-185.

Sutton, J. (1991), Sunk Cost and Market Structure, Cambridge, MIT Press.

Worthington, P.R. (1995), "Investment, cash flow and sunk costs," The Journal of Industrial Economics, 153, 49-61.

Zarnowitz, V. and Lambros, L. A. (1987), "Consensus and uncertainty in economic prediction,” Journal of Political Economy, 95, 591-621. 
Figure 1: Ratios of Disposals to Acquisitions by Asset Class

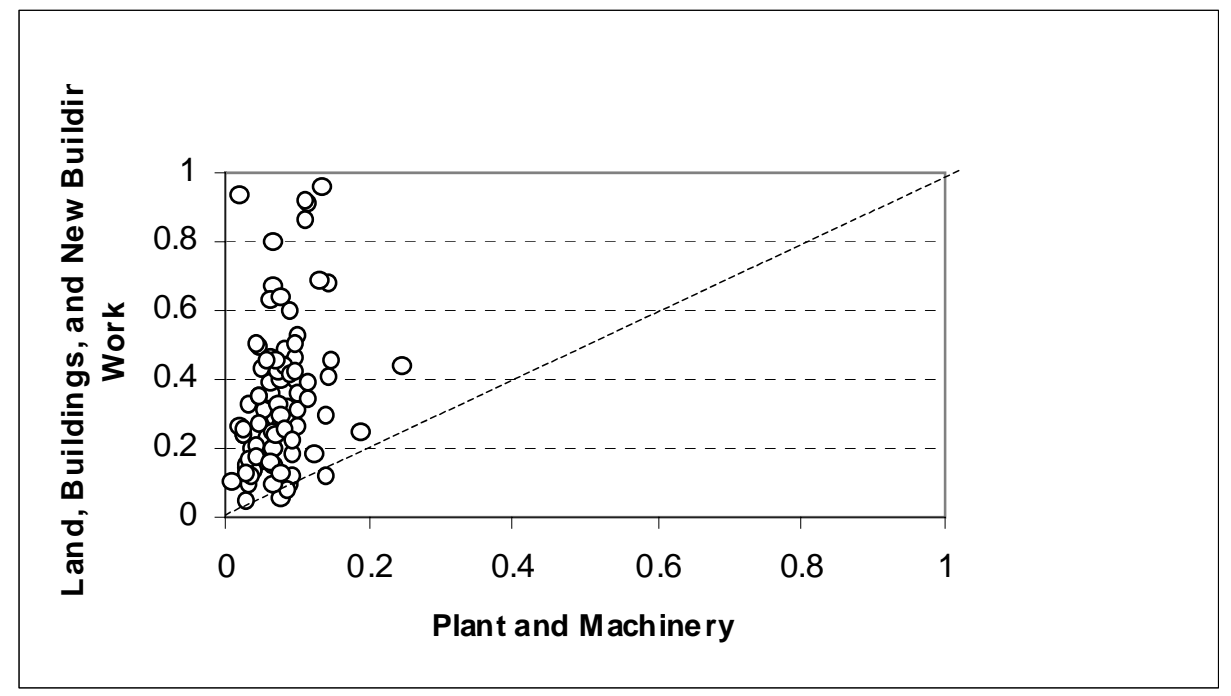

Note: Industries with ratios greater than one have been excluded 


\section{FIGURE 2:}

Impact of an Increase in the Mean Preserving Spread

(Adaptation of Abel et al 1996)

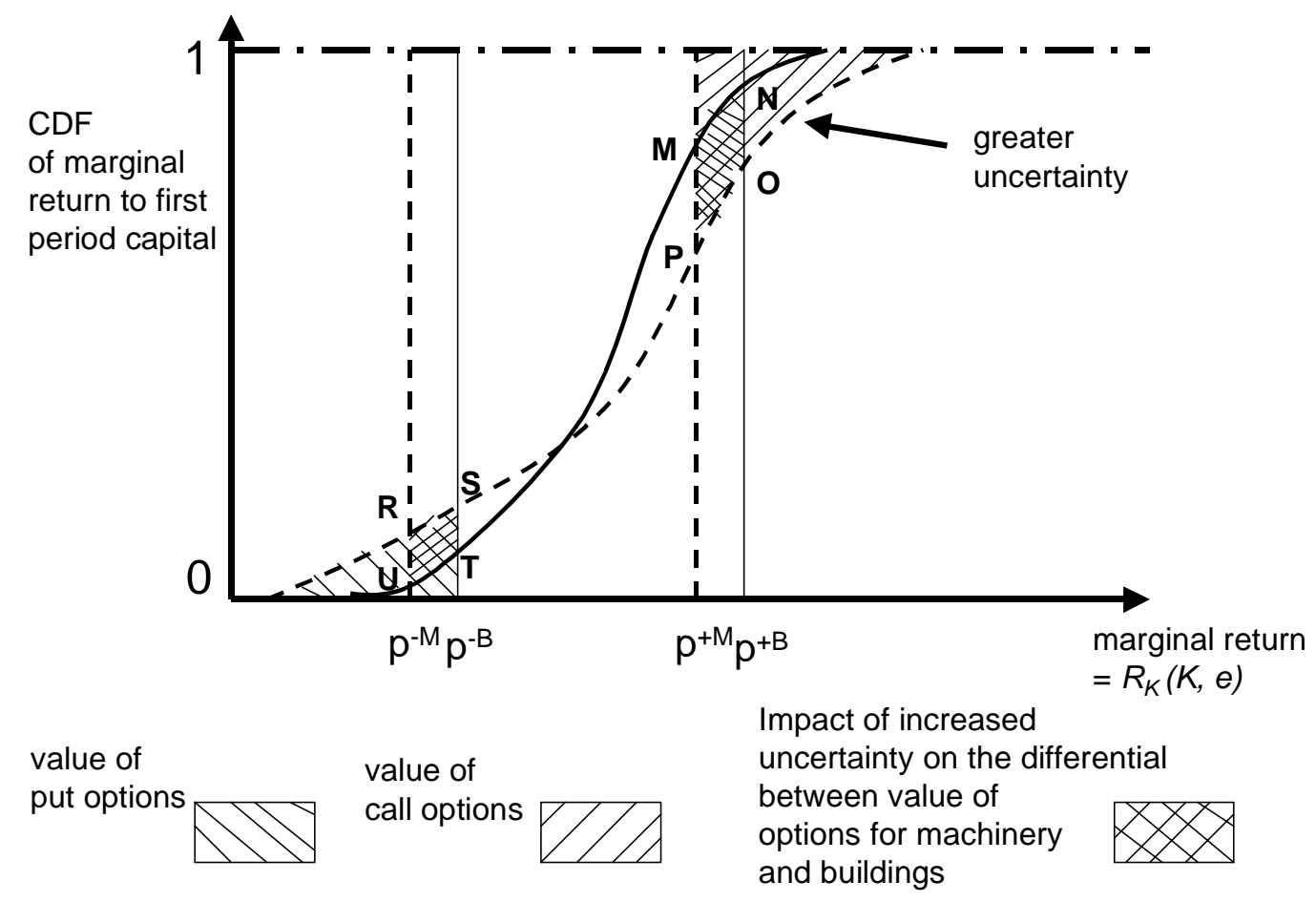


Table 1: Prediction of the relative magnitude of uncertainty coefficients for four panels

\begin{tabular}{|l|l|l|}
\hline & Machinery & Building \\
\hline $\begin{array}{l}\text { Positive uncertainty } \\
\text { coefficients panel }\end{array}$ & Less positive than building & More positive than machinery \\
\hline $\begin{array}{l}\text { Negative uncertainty } \\
\text { coefficients panel }\end{array}$ & More negative than building & Less negative than machinery \\
\hline
\end{tabular}


Table 2: Panel Estimation: Dependent Variable: Investment Authorisation (auth)

\begin{tabular}{|c|c|c|c|c|c|c|c|}
\hline Asset class & Machinery & Buildings & Buildings & Machinery & Machinery & Buildings & Buildings \\
\hline \multirow[t]{2}{*}{ Model } & Fixed Effects & Random-Effects & Fixed Effects & Random-Effects & Random-Effects & Random-Effects & Random-Effects \\
\hline & Full & Full & Full & $\begin{array}{l}\text { Industries with } \\
\text { negative uncertainty } \\
\text { term }\end{array}$ & $\begin{array}{l}\text { Industries with } \\
\text { positive uncertainty } \\
\text { term }\end{array}$ & $\begin{array}{l}\text { Industries with } \\
\text { negative uncertainty } \\
\text { term }\end{array}$ & $\begin{array}{l}\text { Industries with } \\
\text { positive uncertainty } \\
\text { term }\end{array}$ \\
\hline \multirow{3}{*}{ Sample } & Standardized & Standardized & Standardized & Standardized & Standardized & Standardized & Standardized \\
\hline & Coefficients $^{b}$ & Coefficients $^{b}$ & Coefficients $^{b}$ & Coefficients $^{b}$ & Coefficients $^{b}$ & Coefficients $^{b}$ & Coefficients $^{b}$ \\
\hline & $\begin{array}{l}\text { (t-values in } \\
\text { parentheses) }^{\mathrm{c}}\end{array}$ & $\begin{array}{l}\text { (t-values in } \\
\text { parentheses) }^{c}\end{array}$ & $\begin{array}{l}\text { (t-values in } \\
\text { parentheses) }^{\mathrm{c}}\end{array}$ & $\begin{array}{l}\text { (t-values in } \\
\text { parentheses) }^{c}\end{array}$ & $\begin{array}{l}\text { (t-values in } \\
\text { parentheses) }\end{array}$ & $\begin{array}{l}\text { (t-values in } \\
\text { parentheses) }\end{array}$ & $\begin{array}{l}\text { (t-values in } \\
\text { parentheses) }\end{array}$ \\
\hline
\end{tabular}

Explanatory Variables

\begin{tabular}{|c|c|c|c|c|c|c|c|}
\hline auth_1 & 0.28 & 0.28 & 0.26 & 0.37 & 0.21 & 0.28 & 0.17 \\
\hline & $(16.95)^{\star \star}$ & $(16.73)^{\star \star}$ & $(-15.22)^{\star \star}$ & $(8.40)^{\star \star}$ & $(3.74)^{\star \star}$ & $(8.66)^{\star \star}$ & $(2.88)^{\star \star}$ \\
\hline \multirow[t]{2}{*}{ auth_2 } & 0.16 & 0.17 & 0.14 & 0.17 & 0.05 & 0.14 & 0.12 \\
\hline & $(9.60)^{\star \star}$ & $(10.04)^{\star \star}$ & $(8.62)^{\star *}$ & $(3.81)^{\star \star}$ & $(0.98)$ & $(4.33)^{\star \star}$ & $(2.20)^{\star}$ \\
\hline \multirow[t]{2}{*}{ Opt } & 0.19 & 0.15 & 0.15 & 0.21 & 0.28 & 0.16 & 0.18 \\
\hline & $(9.58)^{\star \star}$ & $(6.93)^{\star \star}$ & $(6.94)^{\star \star}$ & $(4.09)^{\star \star}$ & $(3.97)^{\star \star}$ & $(3.72)^{\star \star}$ & $(2.39)^{\star}$ \\
\hline \multirow[t]{2}{*}{$Y f$} & 0.05 & 0.03 & 0.03 & 0.08 & 0.08 & 0.03 & -0.03 \\
\hline & $(3.33)^{\star \star}$ & $(2.08)^{\star}$ & $(1.92)+$ & $(1.99)^{\star}$ & (1. 47) & $(-1.1)$ & $(-0.44)$ \\
\hline \multirow[t]{2}{*}{$Y b$} & 0.07 & 0.08 & 0.08 & 0.03 & 0.06 & 0.08 & 0.01 \\
\hline & $(4.74)^{\star \star}$ & $(4.88)^{\star \star}$ & $(4.84)^{\star \star}$ & $(0.73)$ & (1. 11) & $(2.60)^{\star \star}$ & (0.16) \\
\hline \multirow[t]{2}{*}{$y b \_1$} & 0.08 & 0.06 & 0.06 & 0.09 & 0.09 & 0.12 & 0.05 \\
\hline & $(5.21)^{\star \star}$ & $(3.82)^{\star \star}$ & $(3.83)^{\star \star}$ & $(2.21)^{\star}$ & $(1.71)+$ & $(4.05)^{\star \star}$ & -0.82 \\
\hline \multirow[t]{2}{*}{ cu_1 } & 0.08 & 0.06 & 0.08 & 0.1 & 0.11 & 0.12 & 0.18 \\
\hline & $(2.38)^{\star}$ & $(2.05)^{\star}$ & $(2.31)^{\star}$ & (1. 38) & (0.99) & $(2.03)^{\star}$ & $(1.52)+$ \\
\hline \multirow[t]{2}{*}{ unc } & -0.04 & -0.00 & -0.01 & -0.11 & - & -0.06 & - \\
\hline & $(-2.82)^{\star \star}$ & $(-0.23)$ & $(-0.04)$ & $(-3.18)^{\star \star}$ & - & $(-2.22)^{\star}$ & - \\
\hline \multirow[t]{2}{*}{ unc $(-1)$} & - & -0.01 & -0.01 & - & 0.08 & -0.09 & 0.14 \\
\hline & - & $(-0.42)$ & $(-0.61)$ & - & (1.64)+ & $(-3.26)^{\star \star}$ & $(2.66)^{\star \star}$ \\
\hline \multirow[t]{2}{*}{ unc $(-2)$} & - & 0.02 & 0.01 & -0.08 & - & - & - \\
\hline & - & -1.12 & -0.81 & $(-2.06)^{\star}$ & - & - & - \\
\hline \multicolumn{8}{|l|}{$\begin{array}{l}\text { Sum of unc significant } \\
\text { coefficients [p-value] }\end{array}$} \\
\hline \multirow[t]{2}{*}{ fi_1 } & -0.01 & -0.02 & 0.01 & 0.04 & 0.08 & -0.02 & 0.01 \\
\hline & $(-0.90)$ & $(-1.29)$ & $(-0.12)$ & -1.03 & $(1.86)+$ & $(-0.76)$ & -0.22 \\
\hline \multirow[t]{2}{*}{ Dlcu } & -0.01 & -0.02 & -0.03 & -0.08 & 0.02 & -0.1 & -0.08 \\
\hline & $(-0.19)$ & $(-0.67)$ & $(-1.05)$ & $(-1.15)$ & (0.23) & $(-1.82)+$ & $(-0.71)$ \\
\hline \multirow[t]{2}{*}{ Constant } & -5.97 & -19.96 & -17.69 & 4.72 & -23.21 & -10.19 & -43.73 \\
\hline & $(-1.24)$ & $(-4.46)$ & $(-3.67)^{\star \star}$ & $(0.36)$ & $(-1.33)$ & $(-1.37)$ & $(-2.79)^{\star \star}$ \\
\hline No. of Observations & 3516 & 3515 & 3515 & 546 & 378 & 1014 & 378 \\
\hline $\mathrm{R}^{2}$ & 0.49 & 0.39 & 0.37 & 0.56 & 0.58 & 0.46 & 0.49 \\
\hline \multicolumn{8}{|l|}{ Joint Significance Tests: } \\
\hline F-test (Fixed-effects model) & $36.98^{\star \star}$ & - & $22.62^{\star *}$ & - & - & - & - \\
\hline \multicolumn{7}{|l|}{ (Random Effects model) } & $279.54^{\star *}$ \\
\hline Hausman Test ${ }^{d}$ [p-value] & $\operatorname{chi}^{2}(80)=$ & $\operatorname{chi}^{2}(83)=$ & & $\operatorname{chi}^{2}(81)=$ & $\operatorname{chi}^{2}(83)=$ & $\operatorname{chi}^{2}(84)=$ & $\operatorname{chi}^{2}(83)=$ \\
\hline \multirow{3}{*}{ Breusch-Pagan Test ${ }^{\mathrm{e}}$ [p-value] } & $108.7^{\star \star}[0.01]$ & $63.67[0.9]$ & & $6.97[1.0]$ & $7.84[1.0]$ & $33.49[1.0]$ & $3.08[1.0]$ \\
\hline & $\operatorname{chi}^{2}(861)=$ & $\operatorname{chi}^{2}(861)=$ & $\operatorname{chi}^{2}(861)=$ & $\operatorname{chi}^{2}(21)=$ & $\operatorname{chi}^{2}(10)=$ & $\operatorname{chi}^{2}(78)=$ & $\operatorname{chi}^{2}(10)=$ \\
\hline & $904.01[0.15]$ & $1015 . * *[0.0]$ & 1015.**[0.0] & $37.91 *[0.01]$ & $13.09[0.22]$ & $81.69[0.37]$ & $10.81[0.37]$ \\
\hline The model the test favors & Panel & Unrestricted SURE & Unrestricted SURE & Unrestricted SURE & Panel & Panel & Panel \\
\hline
\end{tabular}

Notes:

(a) time dummies are included in all regressions.

(b) Standardized Coefficient $=$ Estimated coefficient * (standard deviation of explanatory variables/ standard deviation of investment authorization)

(c) ${ }^{\star \star}=$ significant at $1 \%$ level; * = significant at $5 \%$ level; + = significant at $10 \%$ level.

(d) Hausman specification test examines the appropriateness of the fixed vs random effects model.

If the test shows a significant result, the fixed- effects model is chosen over the random-effects model.

(e) Breusch-Pagan test of independence tests the hypothesis that error terms of unrestricted SURE estimation

with the same specification are contemporaneously uncorrelated. 
Table 3: Panel Estimation for Machinery

\section{Model chosen \\ Sample}

Explanatory Variables

\begin{tabular}{|c|c|c|}
\hline auth_1 & 0.27 & 0.27 \\
\hline & $(15.66)^{\star \star}$ & $(15.66)^{\star \star}$ \\
\hline \multirow[t]{2}{*}{ auth_2 } & 0.15 & 0.15 \\
\hline & $(8.97)^{\star \star}$ & $(8.98)^{\star \star}$ \\
\hline \multirow[t]{2}{*}{ opt } & 0.18 & 0.18 \\
\hline & $(8.67)^{\star \star}$ & $(8.68)^{\star \star}$ \\
\hline \multirow[t]{2}{*}{ yf } & 0.06 & 0.06 \\
\hline & $(4.09)^{\star \star}$ & $(4.12)^{\star \star}$ \\
\hline \multirow[t]{2}{*}{$y b$} & 0.07 & 0.07 \\
\hline & $(4.24)^{\star \star}$ & $(4.24)^{\star \star}$ \\
\hline \multirow[t]{2}{*}{$y b \_1$} & 0.07 & 0.07 \\
\hline & $(4.31)^{\star \star}$ & $(4.31)^{\star \star}$ \\
\hline \multirow[t]{2}{*}{$c u \_1$} & 0.1 & 0.1 \\
\hline & $(2.82)^{\star \star}$ & $(2.82)^{\star \star}$ \\
\hline \multirow[t]{2}{*}{ unc } & 0.03 & 0.01 \\
\hline & $(0.98)$ & $(0.19)$ \\
\hline \multirow[t]{2}{*}{ unc *irra d } & -0.15 & - \\
\hline & $(-2.37)$ & - \\
\hline \multirow[t]{2}{*}{ unc *irrb e } & - & -0.09 \\
\hline & - & $(-1.50)$ \\
\hline \multirow[t]{2}{*}{ fi_1 } & -0.02 & -0.02 \\
\hline & $(-1.27)$ & $(-1.33)$ \\
\hline \multirow[t]{2}{*}{ dlcu } & -0.12 & -0.02 \\
\hline & $(-0.55)$ & $(-0.56)$ \\
\hline \multirow[t]{2}{*}{ constant } & -6.85 & 5.86 \\
\hline & $(-1.66)$ & $(-1.50)$ \\
\hline No. of Observations & 3225 & 3225 \\
\hline $\mathrm{R}^{2}$ & 0.4763 & 0.4641 \\
\hline \multicolumn{3}{|l|}{ Joint Significance Tests: } \\
\hline F-test (for fixed-effects model) & $33.95^{\star \star}$ & $32.50 * *$ \\
\hline \multirow[t]{2}{*}{ Hausman Test [p-value] } & $\operatorname{chi}^{2}(82)=$ & $\operatorname{chi}^{2}(82)=$ \\
\hline & $92.04[0.23]$ & $101.84+[0.068]$ \\
\hline
\end{tabular}

Fixed Effects

Full

Standardized Coefficients ${ }^{b}$

(t-value)
Fixed Effects

Full

(t-value)
Standardized Coefficients ${ }^{b}$

Notes: See Table 2. 


\section{APPENDIX 1: CBI Data and Variable Definitions}

\section{The $\mathrm{CBI}$ Industrial Trends Survey}

In this paper, we draw upon the Industrial Trends Survey carried out by the main employers' organisation, the Confederation of British Industry (CBI) with over 1000 replies on average each quarter. It has been published on a regular basis since 1958 and has been widely used by economists. Our panel data set is restricted to the period 1978 Q1 to 1999 Q1, since the question on authorisation of investment was added in 1978. The responses in the survey are weighted by net output with the weights being regularly updated. The survey sample is chosen to be representative and is not confined to $\mathrm{CBI}$ members

Survey Questions

CBI Industrial Trends Survey Questions

Question 1

Are you more, or less, optimistic than you were four months ago about the general business situation in your industry?

Question $3 b$

Do you expect to authorise more or less capital expenditure in the next twelve months than you authorised in the past twelve months on: machinery? (Possible Choices: 'More', 'Same' or 'Less')

\section{Question 4}

Is your present level of output below capacity (i.e., are you working below a satisfactory full rate of operation)? ('Yes', or 'No')

\section{Question 8}

Excluding seasonal variations, what has been the trend over the PAST FOUR MONTHS, and what are the expected trends for the NEXT FOUR MONTHS, with regard to: Volume of output? ('Up', 'Same' or 'Down')

\section{Question 16(c)}

Part C of the question invites respondents to consider which factors are "expected to limit capital expenditure authorisations over the next twelve months". We aggregate the following reply categories

- a shortage of internal finance;

- an inability to raise external finance;

\section{Variable Definitions}

The variables are constructed as transformations of the qualitiative data in the Survey using balance of up(more) over down(less). See Smith and McAleer (1995), Driver and Urga (2004).

auth: based on the balance of more over less from Question 3b

$y_{b}$ : based on balance of ups over downs (PAST) from Question 8

Specifically, the first term on the right of (2) is obtained using a Taylor approximation as: $\Delta \log \Delta Y_{t}=\left[\Delta \log Y_{t}+\Delta \Delta \log Y_{t}\right]$

This is equal to the sum of the survey balance plus the first difference of that balance.

$y_{f}$ : based on balance of ups over downs (NEXT) from Question 8 
opt: based on balance of $\mathrm{m}$ ore over less from Question 1

fi: based responses to internal and external finance constraints from Question 16c

$c u$ : based on logit of \% NO response from Question 4

The equilibrium correction term in (2) is obtained by proxying the unknown level of authorisations $A_{t}$ by the change in the capital stock $\left(\Delta K_{t}\right)$, on the assumption of proportional depreciation and in the light of the close correspondence between authorised and actual investment found from the realisation studies cited in the text. Writing $\log (\Delta K / \Delta Y)_{t-1}=\log \left[\left(K_{t-1} / \Delta Y_{t-1}\right)-\left(K_{t-2} / \Delta Y_{t-1}\right)\right]$

Using a Taylor approximation we may write the RHS term as:

$\left[\log \left(K_{t-1} / \Delta Y_{t-1}\right)\right]-\left(K_{t-2} / K_{t-1}\right)$

$=\left[\log K_{t-1}-\log \Delta Y_{t-1}\right]+\left(K_{t-1}-K_{t-2}\right) / K_{t-1}-1$

$\approx \log K_{t-1}-\log \Delta Y_{t-1}+\Delta \log K_{t-1}-1$

Again using a Taylor approximation for $\log \Delta Y_{t-1}\left(=\log Y_{t-1}-Y_{t-2} / Y_{t-1}\right)$ :

$=\log K_{t-1}-\log Y_{t-1}+Y_{t-2} / Y_{t-1}+\Delta \log K_{t-1}-1$

$\approx \log (K / Y)_{t-1}+\Delta \log (K / Y)_{t-1}$

$=-[\log (Y / K)+\Delta \log (Y / K)]_{t-1}$

Where $(Y / K)_{t}$ is an indicator of capacity utilisation that is measured from the survey as the percentage of firms reporting capacity utilisation above normal (\% answering "NO" to question 4 of the survey).

dlcu: first difference term in logit of \% NO response from Question 4

unc: based on responses to the survey question on industry optimism, Question 1. Specifically, this is the entropy of the three replies (up/same/down). Writing $S_{j}$ for the share of reply $j, j=1,3$ we define: unc $=\Sigma\left[-S_{j} \log S_{j}\right]$. An even spread in the replies (each share $S_{i}$ equal to one third) corresponds to maximum entropy and maximum uncertainty. It may be noted that the question relates to optimism in respect of the industry rather than the firm so that the dispersion recorded should not reflect different objective circumstances but rather different expectations in respect of a common variable 


\section{TABLE A1}

\section{CBI Table Industry}

no

22

23

24

25

26

27

28

29

30

31

32

33

34

35

36

37

38

39

40

41

42

43

44

45

46

47

48

49

50

51

52

53

54

55

56

57

58

59

60

61

62

63

64

65

66

67

68

69

70

71

Food

Footwear
Coal and petroleum products

Extraction of minerals and metaliiferous ores

Ferrous metals

Non-ferrous metals

building materials

glass and ceramics

industrial chemicals

agricultural chemicals

pharmaceuticals and consumer chemicals

man-made fibres

foundries; and forging, pressing, stamping

metal goods nes

hand tools and implements

constructional steelwork

heavy industrial plant

agricultural machinery

metal working machine tools

engineers small tools

industrial machinery

contractors' plant

industrial engines, pumps, compressors

heating, ventilating and refrigerating equipment

other mechanical engineering

office machinery and data processing equipment

electrical industrial goods

elctronic industrial goods

electrical consumer goods

electronic consumer goods

motor vehicles

Shipbuilding

aerospace and other vehicles

instrument engineering

drink and tobacco

wool textiles

spinning and weaving

hosiery and knitwear

textile and consumer goods

other textiles

leather and leather goods

clothing and fur

timber and wooden products other than furniture

furniture, upholstery, bedding

pulp,paper, and board

paper and board products

printing and publishing

rubber products

plastics products

other manufacturing

\section{SIC codes}

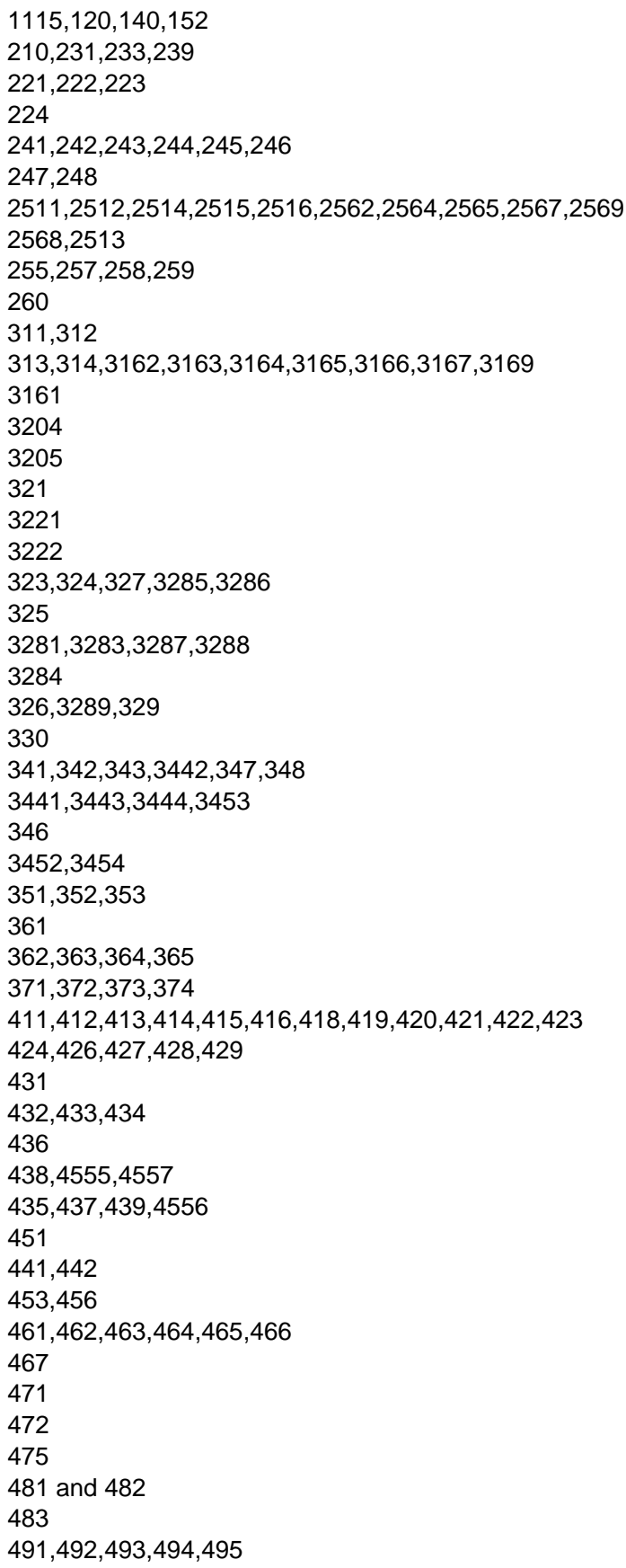

$491,492,493,494,495$ 


\section{APPENDIX 2: Summary Statistics on Unrestricted SURE Results}

\section{CBI classification and Industry}

\begin{tabular}{|c|c|c|c|c|c|}
\hline & & \multicolumn{2}{|c|}{ Machinery } & \multicolumn{2}{|c|}{ Buildings } \\
\hline & & $\mathbf{R}^{2}$ & DW & $\mathbf{R}^{2}$ & DW \\
\hline 24 & Ferrous metals & 0.63 & 1.85 & 0.56 & 1.90 \\
\hline & Non-ferrous metals & 0.49 & 1.79 & 0.34 & 2.15 \\
\hline 26 & Building materials & 0.71 & 2.15 & 0.56 & 1.80 \\
\hline 27 & Glass and ceramics & 0.81 & 2.25 & 0.77 & 2.05 \\
\hline 28 & Industrial chemicals & 0.57 & 2.04 & 0.46 & 2.04 \\
\hline 30 & Pharmaceuticals and consumer & 0.42 & 2.11 & 0.41 & 1.86 \\
\hline 32 & Foundries; and forging, pressing and & 0.67 & 2.11 & 0.68 & 2.00 \\
\hline 33 & Metals goods n.e.s. & 0.77 & 2.28 & 0.65 & 1.87 \\
\hline 34 & Hand tools and implements & 0.69 & 2.20 & 0.61 & 2.19 \\
\hline 35 & Constructional steelwork & 0.66 & 2.13 & 0.44 & 1.88 \\
\hline 36 & Heavy industrial plant & 0.19 & 2.08 & 0.14 & 2.09 \\
\hline 37 , & Agricultural machinery & 0.51 & 1.80 & 0.28 & 1.92 \\
\hline 38 & Metal working machine tools & 0.54 & 2.23 & 0.47 & 2.13 \\
\hline 39 & Engineer's small tools & 0.63 & 1.79 & 0.62 & 2.11 \\
\hline 40 & Industrial machinery & 0.50 & 2.46 & 0.54 & 2.20 \\
\hline 41 & Contractors' plant & 0.63 & 1.58 & 0.61 & 1.99 \\
\hline 42 & Industrial engines, pumps and & 0.52 & 1.69 & 0.39 & 2.04 \\
\hline 43 & Heating, ventilating and refrigerating & 0.53 & 2.17 & 0.51 & 1.73 \\
\hline 44 & Other mechanical equipment & 0.73 & 2.13 & 0.47 & 1.99 \\
\hline 46 & Electrical industrial goods & 0.39 & 2.02 & 0.24 & $2.29^{*}$ \\
\hline 47 & Electronic industrial goods & 0.41 & 2.21 & 0.29 & 1.99 \\
\hline 48 & Electrical consumer goods & 0.58 & 1.90 & 0.34 & 2.11 \\
\hline 49 & Electronic consumer goods & 0.35 & 1.99 & 0.28 & 1.79 \\
\hline 50 & Motor vehicles & 0.58 & 2.28 & 0.40 & 2.02 \\
\hline 52 & Aerospace and other vehicles & 0.38 & 1.89 & 0.42 & 2.06 \\
\hline 53 & Instrument engineering & 0.41 & 1.83 & 0.31 & 2.24 \\
\hline 54 & Food & 0.34 & 2.25 & 0.49 & 2.25 \\
\hline 55 & Drink and Tabacco & 0.26 & 1.86 & 0.26 & 1.89 \\
\hline 56 & Wool textiles & 0.58 & 2.19 & 0.59 & 2.01 \\
\hline 57 & Spinning and weaving & 0.69 & 1.64 & 0.38 & 1.84 \\
\hline 58 & Hosiery and knitwear & 0.51 & 1.69 & 0.28 & 2.04 \\
\hline 59 & Textile consumer goods & 0.38 & 2.21 & 0.48 & 1.98 \\
\hline 61 & Footwear & 0.54 & 2.27 & 0.48 & 2.33 \\
\hline 62 & Leather and leather goods & 0.67 & 2.04 & 0.67 & 2.05 \\
\hline 63 & Closing and fur & 0.63 & 2.02 & 0.61 & 1.90 \\
\hline 64 & Timber and wooden products other & 0.69 & 1.99 & 0.70 & 1.94 \\
\hline 65 & Furniture, upholstery and bedding & 0.68 & 2.25 & 0.65 & 2.39 \\
\hline 66 & Pulp, paper and board & 0.52 & 1.95 & 0.38 & 1.92 \\
\hline 67 & Paper and board products & 0.51 & 2.05 & 0.50 & 2.10 \\
\hline 68 & Printing and publishing & 0.56 & 2.35 & 0.40 & 1.92 \\
\hline 69 & Rubber products & 0.58 & 2.00 & 0.57 & 2.23 \\
\hline 70 & Plastic products & 0.61 & 2.06 & 0.51 & 2.15 \\
\hline
\end{tabular}




\begin{tabular}{|c|c|c|c|c|c|c|}
\hline CBI classification and Industry* & $\begin{array}{l}\text { Industries } \\
\text { with Negative } \\
\text { and significant } \\
\text { Coefficient in } \\
\text { SURE estimation } \\
\text { Estimation for } \\
\text { Machinery } \\
\text { Investment }\end{array}$ & $\begin{array}{l}\text { Industries } \\
\text { with Positive } \\
\text { and significant } \\
\text { Coefficient in } \\
\text { SURE estimation } \\
\text { Estimation for } \\
\text { Machinery } \\
\text { Investment } \\
\end{array}$ & $\begin{array}{l}\text { Industries } \\
\text { with Negative } \\
\text { and significant } \\
\text { Coefficient in } \\
\text { SURE } \\
\text { Estimation for } \\
\text { Building } \\
\text { Investment } \\
\end{array}$ & $\begin{array}{l}\text { Industries } \\
\text { with Positive } \\
\text { and significant } \\
\text { Coefficient in } \\
\text { SURE estimation } \\
\text { Estimation for } \\
\text { Building } \\
\text { Investment } \\
\end{array}$ & $\begin{array}{c}\text { Reverse } \\
\text { Ranking of } \\
D / A \\
\text { (irra) }^{x_{a}}\end{array}$ & $\begin{array}{c}\text { Reverse } \\
\text { Adjusted } \\
\text { Ranking of } \\
\text { D/A } \\
\text { (irrb) }\end{array}$ \\
\hline 23 Coal and petroleum product & & & & & 30 & 19 \\
\hline 24 Ferrous metals & & & & & 43 & 44 \\
\hline 25 Non-ferrous metals & & & & & 40 & 34 \\
\hline 26 Building materials & & & $\mathbf{x}$ & & 38 & 37 \\
\hline 27 Glass and ceramics & & & & & 41 & 38 \\
\hline 28 Industrial chemicals & & & $\mathbf{x}$ & & 24 & 45 \\
\hline 30 Pharmaceuticals and consumer chemicals & $\mathbf{x}$ & & $\hat{x}$ & & 39 & 41 \\
\hline 32 Foundries; and forging, pressing and stamping & ה & & ^ & & 31 & $\begin{array}{l}41 \\
24\end{array}$ \\
\hline 33 Metals goods n.e.s. & & & $\mathbf{x}$ & & 14 & 23 \\
\hline 35 Constructional steelwork & $\mathbf{x}$ & & $\hat{x}$ & & 12 & 9 \\
\hline 36 Heavy industrial plant & & & $\mathrm{x}$ & & 13 & 10 \\
\hline 37 Agricultural machinery & & & & & 42 & 36 \\
\hline 38 Metal working machine tools & & & & & 2 & 2 \\
\hline 39 Engineer's small tools & & $\mathbf{x}$ & & & 3 & 3 \\
\hline 40 Industrial machinery & & & & & 9 & 20 \\
\hline 41 Contractors' plant & & & & & 6 & 4 \\
\hline 42 Industrial engines, pumps and compressors & & $\mathbf{x}$ & & $\mathrm{x}$ & 19 & 27 \\
\hline 43 Heating, ventilating and refregiating equipment & & & $\mathbf{x}$ & & 20 & 28 \\
\hline 44 Other mechanical equipment & & & & $\mathbf{x}$ & 11 & 25 \\
\hline 45 Office machinery and data processing & & & & & 21 & 16 \\
\hline 46 Electrical industrial goods & & & & & 10 & 31 \\
\hline 47 Electronic industrial goods & & $\mathbf{x}$ & & $\mathbf{x}$ & 23 & 30 \\
\hline 48 Electrical consumer goods & & & & & 44 & - \\
\hline 49 Electronic consumer goods & & $\mathbf{x}$ & & $\mathbf{x}$ & 22 & 22 \\
\hline $\begin{array}{l}50 \\
51 \\
51 \text { Shipbuilding }\end{array}$ & & & & & $\begin{array}{l}18 \\
15\end{array}$ & $\begin{array}{l}43 \\
11\end{array}$ \\
\hline 52 Aerospace and other vehicles & & & & & 36 & 33 \\
\hline 53 Instrument engineering & & & & & 27 & 21 \\
\hline 54 Food & $\mathbf{x}$ & & $\mathbf{x}$ & & 26 & 39 \\
\hline 55 Drink and Tabacco & $\mathrm{x}$ & & $\mathrm{x}$ & & 34 & 35 \\
\hline \begin{tabular}{l|l}
56 & Wool textiles \\
57 & Spinning and weaving
\end{tabular} & $\mathbf{x}$ & & & & 8 & 7 \\
\hline $\begin{array}{l}57 \\
58 \\
58 \text { Spinning and weaving } \\
\text { Hosiery and knitwear }\end{array}$ & & & $\mathbf{x}$ & & 1 & 1 \\
\hline 59 Textile consumer goods & & & & & 37 & 29 \\
\hline 61 Footwear & & & & & 33 & 17 \\
\hline 62 Leather and leather goods & & & & & 32 & 14 \\
\hline 63 Closing and fur & & & & & 17 & 12 \\
\hline 64 Timber and wooden products other than furniture & & $\mathbf{x}$ & & $\mathbf{x}$ & 16 & 13 \\
\hline 65 Furniture, upholstery and bedding & & & & & 25 & 15 \\
\hline 66 Pulp, paper and board & $\mathbf{x}$ & & $\mathrm{x}$ & & 45 & 42 \\
\hline 67 Paper and board products & & & $\hat{x}$ & & 5 & 6 \\
\hline $\begin{array}{l}68 \\
69 \text { Printing and publishing } \\
\text { Rubber products }\end{array}$ & $\mathrm{x}$ & & $\mathrm{x}$ & & 4 & 8 \\
\hline $\begin{array}{l}69 \\
70 \\
\end{array}$ & & & & & 28 & 32 \\
\hline
\end{tabular}

*Industries that are omitted from the table are those with missing observations for either CBI survey data for the data on disposal or acquisition. 